\title{
Aid in the Aftermath of Hurricane Katrina: Inferences of Secondary Emotions and Intergroup Helping
}

\author{
Amy J. C. Cuddy \\ Northwestern University \\ Mindi S. Rock \\ University of Massachusetts - Amherst
}

Michael I. Norton

Harvard Business School

\begin{abstract}
This research examines inferences about the emotional states of ingroup and outgroup victims after a natural disaster, and whether these inferences predict intergroup helping. Two weeks after Hurricane Katrina struck the southern United States, White and non-White participants were asked to infer the emotional states of an individualized Black or White victim, and were asked to report their intentions to help such victims. Overall, participants believed that an outgroup victim experienced fewer secondary, 'uniquely human' emotions (e.g. anguish, mourning, remorse) than an ingroup victim. The extent to which participants did infer secondary emotions about outgroup victims, however, predicted their helping intentions; in other words, those participants who did not dehumanize outgroup victims were the individuals most likely to report intentions to volunteer for hurricane relief efforts. This investigation extends prior research by: (1) demonstrating infraglobalhumanization of individualized outgroup members (as opposed to aggregated outgroups); (2) examining infrahumanization via inferred emotional states (as opposed to attributions of emotions as stereotypic traits); and (3) identifying a relationship between infra-humanization of outgroup members and reduced intergroup helping.
\end{abstract}

KEYWORDS discrimination, emotions, helping, Hurricane Katrina, infrahumanization, intergroup, prejudice, racism

Perhaps the most shocking development in the aftermath of the Hurricane Katrina disaster was the sluggish and inadequate response to victims who were clearly in dire need of assistance. Even after extensive mainstream

\author{
Author's note \\ Address correspondence to Amy \\ Cuddy, Kellogg School of Management, \\ Northwestern University, 2001 Sheridan Rd., \\ Evanston, IL 60208, USA [a-cuddy@kellogg. \\ northwestern.edu.]
}


news coverage of the miserable conditions at the Convention Center and Superdome in New Orleans, days passed before water, food, and medical supplies were delivered and before victims were finally evacuated. Michael Brown, the Director of the Federal Emergency Management Agency, famously joked in emails about how his clothing looked on television as he failed to respond to emails which-with increasingly frantic tones-described the unfolding crisis (Associated Press, 2005). Why was Brown's response, and the response of others responsible for handling the crisis, so muted and delayed? Was there something about those responsible for helping that impeded the helping response? Was there something about those who needed help that failed to motivate those responsible to engage? We suggest that it was a combination of the two: the particular mix of those responsible for helping and those in need of help obstructed the realization of an adequate helping response.

Specifically, this research examines how differences in observers' beliefs about the emotional anguish of victims may have contributed to the inadequate response following Hurricane Katrina, whose victims disproportionately were Black, Latino, and poor (Branch, 2005; Gelineau, 2005; The Washington Post, 2005). After encountering tremendous stress and loss, many of the victims were likely experiencing complex and intense emotions such as grief, mourning, and dismay. We propose that the modal consumer of news coverage of Katrina-middle-class White Americans-failed to perceive Katrina victims as experiencing those emotions, and that this denial enervated the overall helping response.

People are more likely to help an ingroup member than an outgroup member (Hornstein, 1978; Levine, Prosser, Evans, \& Reicher, 2005; Turner, Hogg, Oakes, Reicher, \& Wetherell, 1987). The present research aims to shed light on why people display an intergroup helping bias, by examining how people's inferences about the emotional states of victims may both trigger and impede helping responses to outgroups. We emphasize the role of intergroup bias in this process, predicting that: (a) people will perceive outgroup victims as experiencing less emotional anguish than ingroup victims (both Whites observing Black victims, and nonWhites observing White victims); and (b) these differences will predict willingness to come to the aid of members of outgroups.

\section{Ascribing emotions to ingroups vs. outgroups}

How are emotions ascribed to ingroups and outgroups? A recent social psychological account comes from the social identity perspective, uniting the concepts of ingroup favoritism (Brewer \& Brown, 1998) and subjective essentialism (Corneille \& Leyens, 1994; Rothbart \& Taylor, 1992). Leyens and colleagues (2000, 2001, 2003; Demoulin et al., 2004) describe how people are motivated to reserve the 'uniquely human' essence for ingroups and to withhold it from outgroups. This phenomenon'infrahumanization'-involves ascribing greater intelligence (Crocker, Major, \& Steele, 1998) and language competency (Giles \& Coupland, 1991) to ingroups, while denying outgroups those same competencies (Harris \& Fiske, in press).

Infrahumanization also involves attributing to outgroups less capacity for feeling a full range of emotions (see Leyens et al., 2003 for a review). This theoretical approach differentiates primary emotions, such as pleasure, fear, and rage, from secondary emotions, such as admiration, resentment, and disappointment (Demoulin et al. 2004). The former are believed to be experienced by both human and non-human animals; the latter are believed to be experienced exclusively by humans. Perceivers associate primary emotions, which do not impart a human essence, equally with ingroups and outgroups. However, perceivers consistently associate more uniquely human (i.e. secondary) emotions with ingroups than with outgroups, a finding that is robust across varied intergroup contexts: Frenchspeaking (i.e. Walloonian) and Dutch-speaking (i.e. Flemish) Belgians (Paladino et al., 2002), Italians and North Africans (Vaes, Paladino, Castelli, Leyens, \& Giovanazzi, 2003), and White 
Americans and Native Americans (Castano \& Giner-Sorolla, 2006), among others. It should also be noted that, intergroup social status differences do not moderate the ascription of more secondary emotions to ingroups than to outgroups; high status groups infrahumanize low status groups, and vice versa.

\section{Inferring emotional states of individualized outgroup members}

Thus far, researchers have not demonstrated infra-humanization of individualized outgroup members (Cortes et al., 2002 as cited in Leyens et al., 2003). That is, when an outgroup member is individualized, or personalized, by a first and last name, infrahumanization seems to vanish. Leyens and colleagues interpret these findings as evidence that infrahumanization is an intergroup, not an interpersonal, phenomenon (Leyens et al., 2003). ${ }^{1}$ However, in most of these studies, participants were asked to ascribe emotions as traits of groups by indicating whether a list of emotions characterize a given group (e.g. Leyens et al., 2001; Paladino et al., 2002; Vaes et al., 2003). In other words, participants were not asked to infer the emotional states of a group member in response to a given situation-how that person might be feeling-but whether or not the emotions are stereotypic traits of the group or group member.

The present research examines how perceivers infer emotions as states of individualized group members. People use different strategies for inferring mental states (such as emotions) of members of ingroups versus outgroups. Projection-using the self as a prototype to infer another's mental state-is used to infer the mental states of similar others and ingroup members, while stereotyping-using generalized beliefs about a social group to infer another's mental state-is used to infer the mental states of dissimilar others and outgroup members (Ames, 2004a, 2004b). Because most individuals experience both primary and secondary emotions themselves, they should project both kinds of emotions onto members of ingroups when inferring emotions; because people stereotype outgroups as experiencing fewer uniquely human emotions than ingroups, they should be less likely to infer secondary emotions about members of an outgroup. We hypothesize that when participants are asked to infer the emotional state of a Hurricane Katrina victim, they will infer fewer secondary emotions when that victim is an outgroup member than when that victim is an ingroup member, but their inferences of primary emotions will not differ.

\section{Emotion inferences and intergroup helping}

How might these differences in inferred emotional states relate to intergroup behavior, in this case helping responses to Katrina victims? We propose that humanization (i.e. inferences of higher secondary emotions) of individual outgroup victims promotes intergroup helping by personalizing and increasing the perceived similarity to the outgroup member. First, people are more generous toward personalized victims than they are toward aggregated victims (Small \& Loewenstein, 2003). For example, using personalizing (i.e. humanizing) information to single out an individual child with cancer, rather than referring to a group of children with cancer, greatly increases donations to cancer funds (Kogut \& Ritov, 2005a, 2005b). Second, and more pertinent to the present research, both empathizing with an outgroup (Batson, Chang, Orr, \& Rowland, 2002; Batson et al., 1997) and actively considering an outgroup member's point of view (i.e. perspective-taking; Galinsky \& Ku, 2004; Galinsky \& Moskowitz, 2000; Vescio, Sechrist, \& Paolucci, 2003) can ameliorate intergroup relations and facilitate intergroup helping. Empathy is elicited, in part, by viewing the other as similar to the self or the ingroup (Batson, Turk, Shaw, \& Klein, 1995; but also see Batson, Lishner, Cook, \& Sawyer, 2005). Experiencing empathy can also increase the perceived similarity to the target, which has been shown to mediate the link between empathy and helping (Sturmer, Snyder, Kropp, \& Siem, 2006). From an evolutionary perspective, empathy renders the other's needs self-relevant 
(Cialdini, Brown, Lewis, Luce, \& Neuberg, 1997) and sensitizes perceivers to exactly what those needs are (Sibicky, Schroeder, \& Dovidio, 1995), thus eliciting helping responses. Similarly, by creating an overlap between the self and the outgroup (Galinsky \& Moskowitz, 2000), perspective-taking increases perceived similarity and encourages helping responses to outgroup members.

By considering the distinction between inferences of primary versus secondary emotions, we hope to theoretically refine the relationship between empathy and intergroup helping. The core idea of infrahumanization is that, by attributing fewer secondary (but equal primary) emotions to outgroups, perceivers deny them the human essence, which they reserve for the ingroup. This denial of the experience of secondary emotions should decrease the perceived similarity, or overlap, between the ingroup and the outgroup, thus impeding help-giving. On the other hand, humanizing an outgroup-via the attribution of secondary emotions-should increase the perceived similarity between the ingroup and the outgroup, thus facilitating help-giving. In sum, we hypothesize that inferences of higher secondary-but not primary-emotions about an outgroup victim will increase the likelihood that the perceiver will offer help.

Why would secondary emotions more strongly predict intergroup helping than intragroup helping? We suggest that, because inferences of secondary emotions are normative when observing members of the ingroup (e.g. Leyens et al., 2001), they are not diagnostic in predicting ingroup-directed behavior. For outgroups, on the other hand, inferences of secondary emotions are rare, possibly making such inferences highly salient-and possibly highly diagnostic-in predicting behavior toward outgroups; we explore this possibility in the study below.

\section{Summary of hypotheses}

The present study tested two hypotheses. First, we predict that participants will infer higher secondary emotions about the states of individualized ingroup victims than about individualized outgroup victims, but will not differentiate ingroup and outgroup victims on inferences of primary emotions. Second, we predict that participants who infer lower secondary emotions will be less likely to report intentions to help with Katrina relief efforts. However, we predict that this relationship between infrahumanization and helping intentions will be stronger in intergroup conditions (i.e. non-White participants rating White victim; White participants rating Black victim) than in intragroup conditions. By examining intergroup reactions to victims of an actual disaster shortly after it occurred, we are able to examine these processes in a real-world context.

\section{Preliminary study: Scale development}

We conducted a preliminary study to obtain ratings of the primary emotions (confusion, pain, distress, fear, panic, anger, rage) and secondary emotions (grief, sorrow, mourning, anguish, guilt, remorse, resentment) used in the main study (below). Though previous infrahumanization research has measured both negative and positive emotions, we thought it unlikely that observers would perceive Katrina victims as experiencing positive emotions such a short time after the storm. Also, the inclusion of positive emotion items might have artificially decreased the variance in the ratings on the more relevant negative emotions. Thus, we chose to omit positive emotions and include only negative ones.

Seventy Rutgers University undergraduates volunteered to complete the questionnaire, rating the 14 emotions on four questions: 'Is the ability to experience this emotion exclusive to human beings or can animals also experience it?' (humanity); 'Does the experience of this emotion involve cognitive components, i.e., how much thinking is associated with this emotion?' (cognitive complexity); 'Does the fact that people experience this emotion give us, in your opinion, any idea about their moral nature, about their morality?' (morality); and 'How negative is this emotion?' (valence), using a 5 -point scale $(1=$ not at all, $5=$ extremely $)$. The humanity, cognitive complexity, and morality 
items comprised the primary/secondary scale (see Demoulin et al., 2004). We measured valence to ensure that our two scales did not differ significantly on that variable, a potential confound. As expected, our primary $(M=1.58)$ and secondary $(M=3.31)$ emotions items differed significantly on the primary/secondary scale $(t(12)=8.42, p<.001)$, but did not differ on valence $(t(12)=.28, n s)$.

\section{Method}

\section{Participants}

Participants for the main study were recruited at a New Brunswick, New Jersey train station during morning rush hour approximately two weeks after Hurricane Katrina. The experimenters approached participants and asked, 'Would you be willing to complete a short survey about Hurricane Katrina for \$2?' Participants who complied with the request were given a lettersized self-addressed stamped envelope, which contained the two-page questionnaire and two $\$ 1$ bills.

The experimenters distributed 238 questionnaires, $116(49 \%)$ of which were completed and returned. Of those 116 participants, $51 \%$ were female; $53 \%$ were White, $16 \%$ were Black, $19 \%$ were Asian or Asian-American, $8 \%$ were nonWhite Latino; the remaining $4 \%$ responded 'other' or did not provide race information. Given our focus on a particular intergroup context, we excluded from the analyses the 25 participants who did not self-identify as Black, White, or Latino, reducing our data analysis $n$ to 91 (62 White non-Latino participants, 29 Black and non-White Latino participants). We combined Black and Latino participants because these were the two groups who were disproportionately harmed by Hurricane Katrina (Branch, 2005; Gelineau, 2005; The Washington Post, 2005), and because our subsample of Black participants was not sufficient alone for the analyses. The same approach has been used in other empirical social science research, such as the Boston Federal Reserve Mortgage Lending Study that identified patterns of race discrimination in mortgage lending patterns (Munnell, Tootell, Brown, \& McEneaney, 1996).

\section{Materials and procedure}

Participants read a fictionalized news story about a mother who had lost a child during Hurricane Katrina. We manipulated race by using names more common to Black Americans or White Americans (Bertrand \& Mullainathan, 2004; Levitt \& Dubner, 2005). The victim's surname, Johnson, was held constant across conditions. The story began, 'Two weeks after the storm, Tanesha/ Amanda Johnson has yet to hear word about her 2-year-old son, Tyrell/Joshua, who was with his uncle when Hurricane Katrina hit'. In about 200 words, the article goes on to describe the mother's efforts to find her lost child. We avoided using quotes or descriptions that conveyed information about the victim's emotional state. The child's fate was left unresolved.

On the next page, participants read, 'The following questions concern how Tanesha/Amanda Johnson might have been feeling at the time this story was reported. In your opinion, how much was Tanesha/Amanda Johnson feeling each of the following emotions?' Participants rated the seven secondary emotions (grief, sorrow, mourning, anguish, guilt, remorse, resentment) and the seven primary emotions (confusion, pain, distress, fear, panic, anger, rage), on a 5-point scale $(1=$ not at all to $5=$ extremely $)$.

On the final page, participants were asked whether they intended to volunteer their time to Hurricane Katrina relief efforts (yes/no), and whether they had already volunteered (yes/no).

\section{Results}

\section{Inferred emotions}

Each emotion item was weighted by its rating on the continuous primary/secondary scale, which was centered around the median, from the preliminary study data. From the weighted scores, we created composite measures of primary $(\alpha=.82)$ and secondary $(\alpha=.80)$ emotions.

We submitted the primary and secondary emotions scales to a 2 (Victim Race: Black, White) $\times 2$ (Participant Race: White, Black/ Latino) multivariate analysis of variance (ANOVA). There were no main effects of Victim Race or Participant Race on either of the 
emotions scales. As expected, the Victim Race $\times$ Participant Race interaction was not significant for the primary emotions scale $(F(1,91)=1.96$, $n$ ); participants did not differentiate ingroup victims from outgroup victims when inferring primary emotions. However, the critical Victim Race $\times$ Participant Race interaction for the second ary emotions scale was significant $(F(1,91)=5.62$, $p=.02)$. As shown in Figure 1, the interaction took on the expected form, suggesting that participants made lower secondary emotion inferences for outgroup victims than for ingroup victims. To be certain that only secondary emotions, and not primary emotions, were affected by the intergroup context, we conducted a 2 (Victim Race: Black, White) $\times 2$ (Participant Race: White, Black/Latino) analysis of covariance (ANCOVA) for each type of emotion, entering the other type as a covariate. For secondary emotions, when controlling for primary emotions, the Victim Race $\times$ Participant Race interaction remained nearly significant $(F(1$, $91)=3.60, p=.06)$. For primary emotions, on the other hand, when controlling for secondary emotions the Victim Race $\times$ Participant Race interaction was not significant $(F(1,91)=.07)$, $n s)$. Consistent with prior infra-humanization research, participants demonstrated an intergroup bias in their inferences of secondary, but not primary, emotions.

We conducted more focused comparisons, as well. As predicted, Black/Latino participants inferred lower secondary emotions about the White victim $(M=1.37)$ than about the Black victim $(M=1.77)(t(27)=2.40, p=.02) .{ }^{2}$ White participants' inferences of secondary emotions about Black $(M=1.60)$ and White $(M=1.67)$ victims differed in the predicted direction, but this difference was not significant $(t(60)=.58$, $n s)$. White participants inferred lower secondary emotions than Black/Latino participants about the Black victim $(t(48)=2.08, p<.05)$, and slightly

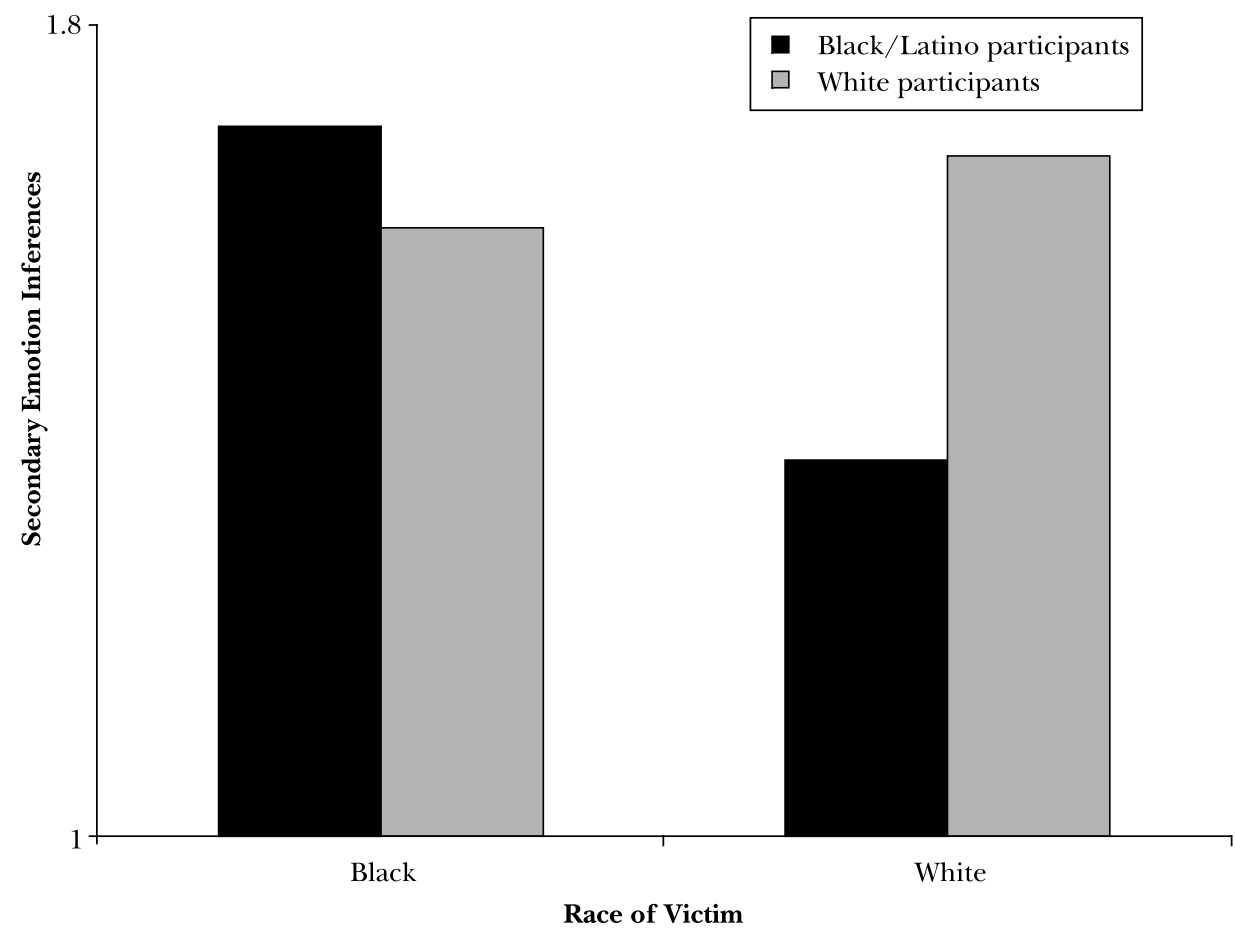

Figure 1. Inferences of secondary emotions by participant race and victim race $(F(1,91)=5.62, p=.02)$. 
higher secondary emotions than Black/Latino participants about the White victim, although this difference was not significant $(t(39)=1.31$, $p=.20)$.

\section{Intentions to help}

We predicted that inferences of higher secondary emotions about outgroup victims would relate to greater intentions to help Hurricane Katrina victims. Given our focus on helping intentions as an outcome of infra-humanization, we excluded from these analyses the 11 participants who reported that they had already volunteered or were currently volunteering for Hurricane Katrina relief efforts. ${ }^{3}$ We conducted binary logistic regression analyses on the aggregated data, entering intention to volunteer (a dichotomous categorical variable) as the dependent variable. Inferred secondary and primary emotions were entered as covariates. As expected, inferences of secondary emotions predicted intentions to volunteer time to help Hurricane Katrina victims, but inferences of primary emotions did not $(\beta=1.95$, Wald $=4.43, p<.05$, and $\beta=-.27$, Wald $=.03$, ns, respectively) ${ }^{4}$

To examine our hypothesis that this effect would be moderated by group context, such that inferences of secondary emotions would predict helping intentions in intergroup, but not intragroup, contexts, the theoretically pertinent analyses required looking at the relationship between inferred emotions and helping intentions separately for the intergroup and intragroup conditions. For intergroup conditions, as hypothesized, inferences of higher secondary emotions predicted intentions to volunteer time $(\beta=3.41$, Wald $=7.14, p<.01)$, but inferences of higher primary emotions did not $(\beta=-1.98$, Wald $=.85, n s)$. For intragroup conditions, however, neither inferences of secondary nor primary emotions predicted intentions to volunteer time $(\beta=-1.11)$, Wald $=.74, n s$, and $\beta=3.55$, Wald $=2.97, n s$, respectively).

\section{Discussion}

The present study provides several novel and intriguing findings. First, when observing the aftermath of a real-life natural disaster, perceivers infra-humanized outgroup victims, denying them the same complexity of emotions that they believed ingroup victims would experience in the same situation. Specifically, people inferred that an individual outgroup victim felt less anguish, via the experience of secondary emotions such as grief, mourning, remorse, and sorrow, than an individual ingroup victim. People did not differentiate ingroup and outgroup victims on inferences of primary emotions, such as fear and sadness, as expected. These findings extend prior infra-humanization research by demonstrating that infra-humanization is not limited to the attribution of emotions as general group traits, but also manifests in inferences of others' emotional states, and that perceivers infra-humanize individualized outgroup members, just as they infra-humanize aggregated outgroups and depersonalized outgroup members.

This research also provides initial evidence that the infra-humanization of outgroup victims has some bearing on how they are treated. Lower inferences of secondary emotions-but not primary emotions-about victims related to reduced intentions to volunteer for Hurricane Katrina relief efforts. This moves beyond a simple empathy $\rightarrow$ helping link, demonstrating the importance of distinguishing primary from secondary emotions. The results imply that empathizing with a victim's experience of primary emotions (e.g. fear) does not lead to greater helping, but empathizing with a victim's experience of secondary emotions (e.g. mourning) does. It is also important to emphasize that group context (i.e. intergroup vs. intragroup) moderated this relationship; the relationship was significant for intergroup conditions, but not for intragroup conditions. In other words, inferring lower secondary emotions about ingroup victims does not relate to helping intentions, but inferring lower secondary emotions about outgroup victims does. To our knowledge, this is the first demonstration of a link between infra-humanization of outgroup victims and helping.

These results are in apparent conflict with previous research suggesting that expressions of secondary emotions by an ingroup and outgroup member elicit opposite responses from the perceiver: people respond positively when 
ingroup members express secondary emotions, but negatively when outgroup members express those same emotions (Vaes et al., 2003). However, we believe that these two sets of results are not incongruous. Specifically, there is a critical difference between an outgroup expressing a secondary emotion and a perceiver inferring a secondary emotion about an outgroup member. In the Vaes et al. studies, outgroup members expressed secondary emotions; in our study, perceivers inferred that an outgroup member was (or was not) feeling secondary emotions. If the expression of secondary emotions by outgroups is counterstereotypic, perceivers might punish deviant outgroup members (Rudman, 1998; Rudman \& Fairchild, 2004). Thus, in the case of a natural disaster, the expression of secondary emotions by outgroup victims might ironically lead to intergroup neglect rather than helping.

Although the predicted Participant Race $\times$ Victim Race interaction was significant for inferences of secondary emotions, Black/ Latino participants clearly infra-humanized White victims more than White participants infra-humanized Black victims. Our post hoc, perhaps cynical, interpretation of this result concerns the intensive media focus on racism that followed Hurricane Katrina, and which seemed to peak during data collection for this study. This unusual attention to the alleged effects of racism may have temporarily sensitized White people to expressions of racism, creating a vigilance to avoid such expressions. Unfortunately, this kind of sensitivity tends to be ephemeral (e.g. Hill \& Augoustinos, 2001), so we suspect that follow-up studies would reveal significant infra-humanization in both directions. Moreover, others have shown that racial and ethnic minority group members express stronger outgroup stereotypes and greater intergroup bias than majority group members (Judd, Park, Ryan, Brauer, \& Kraus, 1995; Verkuyten, 2005). Two explanations have been offered for this difference. First, it has been attributed to differences in social desirability concerns, such that White people in the US are more concerned about appearing racist than members of US racial minority groups (Sommers \&
Norton, 2006). Second, the difference has been attributed to a greater focus on color-blindness and assimilationist thinking by majority group members vs. a greater emphasis on multiculturalism by minority group members (e.g. Judd et al., 1995; Norton, Sommers, Apfelbaum, Pura, \& Ariely, in press).

Some methodological shortcomings should be addressed in futures studies. First, while there is reason to believe Black and Latino victims of Hurricane Katrina would respond similarly (and analyses did indeed reveal identical trends in the Black and Latino subsamples), pooling of Black and Latino participants may have somehow distorted the results. Given practical limitations (i.e. time constraints and inadequate subsample sizes) and evidence that the two racial groups were both disproportionately affected by Hurricane Katrina (Branch, 2005; Gelineau, 2005; The Washington Post, 2005), we combined these subsamples. Second, real behavioral measures are needed to more precisely evaluate the relationship between infra-humanization and intergroup behavior. Third, our data collection method (asking people to return completed questionnaires in a self-addressed stamped envelope) may have overselected a 'helpful' sample of participants, which could have somehow influenced our results on the helping variables. Our ongoing research on this topic addresses these issues.

\section{Future directions}

If infrahumanization of outgroups reduces intergroup helping, then future research should strive to identify the conditions that cause perceivers to humanize outgroups, which should promote intergroup helping. Emphasizing intergroup similarities has proven to be an effective intervention for improving intergroup relations in some contexts (e.g. Brown, 1984; Chen \& Kenrick, 2002, Study 1; Dovidio, Gaertner, Isen, \& Lowrance, 1996; but see also Chen \& Kenrick, 2002, Study 2; Silvia, Graham, \& Hawley, 2005). Taking that idea a step further, priming an inclusive identity (i.e. supplanting 'us' vs. 'them' with just 'us') can activate helping responses toward people formerly seen as outgroup members (Dovidio et al., 1997), even in real 
emergencies (Levine et al., 2005). Moreover, perceived similarity to another person improves the likelihood that a perceiver will use projection when inferring that person's mental state (Ames, 2004a). Thus, evidence suggests that emphasizing intergroup similarity could increase the extent to which perceivers infer secondary emotions from outgroup victims, thereby improving the likelihood of intergroup helping.

The present research suggests that intergroup helping is associated with inferences about the human emotions of those in need. Further investigations should explore the mechanisms by which infra-humanization decreases intergroup helping. We suggest that one category of mediators are the emotions that perceivers themselves experience as a result of making emotion inferences about outgroup victims, or the extent to which they 'catch' the emotions of those individuals via emotional contagion (Hatfield, Cacioppo, \& Rapson, 1994). People are more likely to experience the emotions of others with whom they share a common bond, from pain (Krebs, 1975) to embarrassment (Miller, 1987) to dissonance (Norton, Monin, Cooper, \& Hogg, 2003). What is more, a perceiver who empathizes or sympathizes with an outgroup member is more likely to offer help (Batson et al., 1997; Cuddy, Fiske, \& Glick, in press). Teaching people to humanize outgroups has even been proposed as an effective tool in healing the wounds of past intergroup conflict and reducing the chance of future intergroup conflict (Staub, Pearlman, Gubin, \& Hagengimana, 2005). To the extent that individuals perceive members of outgroups as either similar to themselves, or as experiencing secondary emotions, or both, the tepid response to tragedies when victims are seen as outgroups might be improved.

\section{Notes}

1. A notable exception can be found in Castano \& Giner-Sorolla's (2006) infra-humanization studies, in which participants were asked whether a group has the capacity to feel primary and secondary emotions.

2. The pattern of means for Black participants alone followed the same pattern as found for
Black and Latino participants combined, with higher inferences of secondary emotions for Black victims than for White victims (Black participants: $M \mathrm{~s}=1.81$ and 1.60 , Latino participants: $M \mathrm{~s}=1.70$ and 1.10$)$.

3. Infrahumanization analyses (i.e. analyses looking at effects of participant race and target race on inferences of primary and secondary emotions) without the 11 participants who had already volunteered for relief efforts $(n=80)$ did not differ from the results with the full sample $(n=91)$. For the 2 (Victim Race: Black, White) $\times 2$ (Participant Race: White, Black/ Latino) multivariate ANOVA, the Victim Race $\times$ Participant Race interaction was not significant for the primary emotions scale, but was significant for secondary emotions $(F(1,80)=1.13, n s$, and $F(1,80)=6.25$, $p=.01$, respectively). For the 2 (Victim Race: Black White) $\times 2$ (Participant Race: White, Black/Latino) ANCOVAs (one for each type of emotion, entering the other type as a covariate), inferences of secondary emotions remained significant, and inferences of primary emotions remained nonsignificant $(F(1,80)=5.41, p=.02$, and $F(1,80)=.51, n s$, respectively).

4. Of the 80 participants who had not already volunteered for Katrina relief efforts, $25 \%$ of the participants in the intragroup conditions reported intentions to volunteer and $17 \%$ in the intergroup conditions reported intentions to volunteer. This was not a significant difference $\left(\chi^{2}(1)=.67, n s\right)$.

\section{Acknowledgements}

This research was supported by a National Science Foundation grant (\#0554909) awarded to the first and third authors. We thank Zoe Chen for her help with data collection. We also thank Roger Giner-Sorolla, Jacques-Philippe Leyens, and an anonymous reviewer for helpful feedback on a draft of this manuscript.

\section{References}

Ames, D. R. (2004a). Strategies for social inference: A similarity contingency model of projection and stereotyping in attribute prevalence estimates. Journal of Personality and Social Psychology, 5, 573-585.

Ames, D. R. (2004b). Inside the mind reader's tool kit: Projection and stereotyping in mental 
state inference. Journal of Personality and Social Psychology, 87, 340-353.

Associated Press (2005, November 3). Brown joked in e-mail as Katrina churned. MSNBC. Retrieved July 1, 2006, from http://www.msnbc.msn.com/ id/9912186/.

Batson, C. D., Batson, J. G., Slingsby, J. K., Harrell, K. L., Peekna, H. M., \& Todd, R. M. (1991). Empathic joy and the empathy-altruism hypothesis. Journal of Personality and Social Psychology , 61, 413-426,

Batson, C. D., Chang, J., Orr, R., \& Rowland, J. (2002). Empathy, attitudes and action: Can feeling for a member of a stigmatized group motivate one to help the group? Personality and Social Psychology Bulletin, 28, 1656-1666.

Batson, D. C., Lishner, D. A., Cook, J., \& Sawyer, S. (2005). Similarity and nurturance: Two possible sources of empathy for strangers. Basic and Applied Social Psychology, 27, 15-25.

Batson C. D., Polycarpou M. P., Harmon-Jones E., Imhoff H. J., Mitchener E. C., Bednar L. L. et al. (1997). Empathy and attitudes: Can feeling for a member of a stigmatized group improve feelings toward the group? Journal of Personality and Social Psychology, 72, 105-118.

Batson, C. D., Turk, C. L., Shaw, L. L., \& Klein, T. R. (1995). Information function of empathic emotion: Learning that we value the other's welfare. Journal of Personality and Social Psychology, 68, 300-313.

Bertrand, M., \& Mullainathan, S. (2004). Are Emily and Greg more employable than Lakisha and Jamal? A field experiment on labor market discrimination. American Economic Review, 94, 991-1013.

Branch, A. (2005, November 21). New Orleansarea Honduran residents have extra burden. Duluth News Tribune, Article 13227406. Retrieved November 21, 2005, from http://www. duluthsuperior.com/mld/duluthsuperior/news/ nation/13227406.htm.

Breed, A. G. (2005, September 4). New Orleans left to the dead and dying. Associated Press. Retrieved September 9, 2005, from http://www. ftimes.com/main.asp?Section ID=1.

Brewer, M. B, \& Brown, R. J. (1998). Experimentation in social psychology. In D.T. Gilbert, S.T. Fiske, \& G. Lindzey (Eds.), The handbook of social psychology (Vol. 2, 4th ed.). New York: McGraw-Hill.

Brown, R. J. (1984). The effects of intergroup similarity and cooperative vs. competitive orientation on intergroup discrimination. British Journal of Social Psychology, 23, 21-33.

Castano, E., \& Giner-Sorolla, R. (2006). Not quite human: Infra-humanization as a response to collective responsibility for intergroup killing. Journal of Personality and Social Psychology, 90, 804-819.

Chen, F. F., \& Kenrick, D. T. (2002). Repulsion or attraction? Group membership and assumed attitude similarity. Journal of Personality and Social Psychology, 83, 111-125.

Cialdini, R. B., Brown, S. L., Lewis, B. P., Luce, C., \& Neuberg, S. L. (1997). Reinterpreting the empathy-altruism relationship: When one into one equals oneness. Journal of Personality and Social Psychology, 73, 481-494.

Corneille, O., \& Leyens, J.-Ph. (1994). Catégories, categories sociales et essentialisme psychologique [Categories, socialcategories and psychological essentialism]. In R. Bourhis \& J.-Ph. Leyens (Eds.), Stéréotypes, discrimination et rapports intergroup [Stereotypes, discrimination and intergroup relations]. Liège: Mardaga.

Crocker, J., Major, B., \& Steele, C. (1998). Social stigma. In D. T. Gilbert, S.T. Fiske, \& G. Lindzey (Eds.), The handbook of social psychology (Vol.2, 4th ed.) New York: McGraw-Hill.

Cuddy, A. J. C., Fiske, S. T., \& Glick, P. (in press). The BIAS map: Behavior from intergroup affect and stereotypes. Journal of Personality and Social Psychology.

Demoulin, S., Leyens, J-Ph., Paladino, M.P., Rodrigues-Torres, R., Rodriguez-Perez, A., \& Dovidio, J.F. (2004). Dimensions of 'uniquely' and 'non-uniquely' human emotions. Cognition Eं Emotion, 18, 71-96.

Dovidio, J.F, Gaertner, S.L., Isen, A. M., \& Lowrance, R. (1996). Group representations and intergroup bias: Positive affect, similarity, and group size. Personality and Social Psychology Bulletin, 21, 856-865.

Dovidio, J.F, Gaertner, S.L., Validzic, A., Matoka, K., Johnson, B., \& Frazier, S. (1997). Extending the benefits of recategorization: Evaluations, selfdisclosure, and helping. Journal of Experimental Social Psychology, 33, 401-420.

Galinsky, A. D., \& Ku, G. (2004). The effects of perspective-taking on prejudice: The moderating role of self-evaluation. Personality and Social Psychology Bulletin, 30, 594-604.

Galinsky A. D., \& Moskowitz, G. B. (2000). Perspective-taking: Decreasing stereotype expression, stereotype accessibility, and 
in-group favoritism. Journal of Personality and Social Psychology , 78, 708-724.

Gelineau, K. (2005, November 19). Civil rights leaders: Hispanic immigrants unpaid for Katrina work. The Miami Herald, Article 13212330.

Retrieved November 19, 2005, from http:// www.miami.com/mld/miamiherald/business / national/13212330.htm.

Giles, H., \& Coupland, N. (1991). Language: Contexts and consequences. Montely, CA: Brooks / Cole.

Harris, L. T., \& Fiske, S. T. (in press). Dehumanizing the lowest of the low. New imaging responses to extreme outgoups. Psychological Science.

Hatfield, E., Cacioppo, J.T., \& Rapson, R.L. (1994). Emotional contagion. New York: Cambridge University Press.

Hill, M. E., \& Augoustinos, M. (2001). Stereotype change and prejudice reduction: Short- and long-term evaluation of a cross-cultural awareness programme. Journal of Community $\mathcal{E}^{\circ}$ Applied Social Psychology, 11, 243-262.

Hornstein, H. A. (1978). Promotive tension and prosocial behavior: A Lewinian analysis. In L. Wispé (Ed.), Altruism, sympathy, and helping: Psychological and sociological principles (pp. 177-207). San Diego, CA: Academic Press.

Judd, C. M., Park, B., Ryan, C. S., Brauer, M., \& Kraus, S. (1995).Stereotypes and ethnocentrism: Diverging interethnic perceptions of African American and white American youth. Journal of Personality and Social Psychology, 69, 460-481.

Kogut, T., \& Ritov, I. (2005a). The singularity effect of identified victims in separate and joint evaluations. Organizational Behavior and Human Decision Processes, 97, 106-116.

Kogut, T., \& Ritov, I. (2005b). The 'identified victim' effect: An identified group, or just a single individual? Journal of Behavioral Decision Making, 18, 157-167.

Krebs, D. (1975). Empathy and altruism. Journal of Personality and Social Psychology, 32, 1134-1146.

Levine, M., Prosser, A., Evans, D., \& Reicher, S. (2005). Identity and emergency intervention: How social group membership and inclusiveness of group boundaries shapes helping behavior. Personality and Social Psychology Bulletin, 31, 443-453.

Levitt, S. D., \& Dubner, S. J. (2005, April 17). Trading up: Where do baby names come from? Slate. Retrieved September 9, 2005, from http:/ / www.slate.com/id/2116505.
Leyens, J. P., Cortes, B., Demoulin, S., Dovidio, J. F., Fiske, S. T., Gaunt, R. et al. (2003). Emotional prejudice, essentialism, and nationalism: The 2002 Tajfel Lecture. European Journal of Social Psychology, 33, 703-717.

Leyens, J. P., Paladino, M. P., Rodriguez, R. T., Vaes, J., Demoulin, S., Rodriguez, A. P. et al. (2000). The emotional side of prejudice: The attribution of secondary emotions to ingroups and outgroups. Personality and Social Psychology Review, 4, 186-197.

Leyens, J. P., Rodriguez-Perez, A., RodriguezTorres, R., Gaunt, R., Paladino, M. P., Vaes, J. et al. (2001). Psy chological essentialism and the differential attribution of uniquely human emotions to ingroups and outgroups. European Journal of Social Psychology, 31, 395-411.

Miller, R.S. (1987). Empathic embarrassment: Situational and personal determinants of reactions to the embarrassment of another. Journal of Personality and Social Psychology, 53, 1061-1069.

Munnell, A., Tootell, G. M. B., Brown, L. E., \& McEneaney, J. (1996). Mortgage lending in Boston: Interpreting HMDA data. American Economic Review 86, 25-53.

Norton, M., Monin, B., Cooper, J., \& Hogg, M. (2003) Vicarious dissonance: Attitude change from the inconsistency of others. Journal of Personality and Social Psychology, 85, 47-62.

Norton, M.I., Sommers, S.R., Apfelbaum, E.P., Pura, N., \& Ariely, D. (in press). Colorblindness and interracial interaction: Playing the 'political correctness game.' Psychological Science.

Paladino, M. P., Leyens, J. P., Rodiguez, R. Rodriguez, A. Gaunt, R., \& Demoulin, S. (2002). Differential association of uniquely and non uniquely human emotions with the ingroup and the outgroup. Group Processes EF Intergroup Relations, 5, 105-117.

Rothbart, M., \& Taylor, M. (1992). Category labels and social reality: Do we view social categories as natural kinds? In G.R.Semin \& K. Fiedler (Eds.), Language, interaction and social cognition. Thousand Oaks, CA: Sage Publications.

Rudman, L. A. (1998). Self-promotion as a risk factor for women: The costs and benefits of counterstereotypical impression management. Journal of Personality and Social Psychology, 74, 629-645.

Rudman, L. A., \& Fairchild, K. (2004). Reactions to counterstereotypic behavior: The role of backlash in cultural stereotype maintenance. Journal of Personality and Social Psychology, 87, 157-176. 
Sibicky, M. E., Schroeder, D. A., Dovidio, J. F. (1995). Empathy and helping: Considering the consequences of intervention. Basic and Applied Social Psychology, 16, 435-453.

Silvia, P. J., Graham, J. S., \& Hawley, C. N. (2005). Changing attitudes toward prison reform: Effects of similarity to prisoners on attraction and rejection. Journal of Applied Social Psychology, 35, 248-258.

Small, D.A., \& Loewenstein, G. (2003). Helping a victim or helping the victim: Altruism and identifiability. Journal of Risk and Uncertainity, 26, $5-16$.

Sommers, S.R., \& Norton, M.I. (2006). Lay theories about White racists: What constitutes racism (and what doesn't). Group Processes E् Intergroup Relations, 9, 117-138.

Staub, E., Pearlman, L. A., Gubin, A., \& Hagengimana, A. (2005). Healing, reconciliation, forgiving and the prevention of violence after genocide or mass killing: An intervention and it's experimental evaluation in Rwanda. Journal of Social and Clinical Psychology, 24, 297-334.

Sturmer, S., Snyder, M., Kropp, A., \& Siem, B. (2006). Empathy-motivated helping: The moderating role of group membership. Personality and Social Psychology Bulletin, 32, 943-956.

Turner, J. C., Hogg, M. A., Oakes, P. J., Reicher, S. D., \& Wetherell, M. S. (1987). Rediscovering the social group: A self-categorization theory. Oxford, UK: Basil Blackwell.

Vaes, J., Paladino, M., Castelli, L., Leyens, J. P., \& Giovanazzi, A. (2003). On the behavioral consequences of infra-humanization: The implicit role of uniquely human emotions in intergroup relations. Journal of Personality and Social Psychology, 6, 1016-1034.

Verkuyten, M. (2005). Ethnic group identification and group evaluation among minority and majority groups: Testing the multiculturalism hypothesis. Journal of Personality and Social Psychology, 88, 121-138.
Vescio, T. K., Sechrist, G. B., \& Paolucci, M. P. (2003). Perspective taking and prejudice reduction: The mediational role of empathy arousal and situational attributions. European Journal of Social Psychology, 33, 455- 472.

The Washington Post, Kaiser Family Foundation, \& Harvard University (2005, September). Survey of Hurricane Katrina Evacuees (Publication No. 7401). Retrieved September 15, 2005, from Kaiser Family Foundation: http://www.kff.org/ newsmedia/upload/7401.pdf.

Paper received 6 December 2005; revised version accepted 27 July 2006

\section{Biographical notes}

AMY J. C. CUDDY received her PhD in social psychology from Princeton University in 2005 and is currently an assistant professor of management and organizations at Northwestern University's Kellogg School of Management. Her research explores the roles of stereotypes and emotions in shaping intergroup behavior.

MINDI S. ROCK received her BA in psychology at Oberlin College and is currently a doctoral student in the social psychology program at the University of Massachusetts at Amherst. Her research focuses on prejudice, with an emphasis on predicting intergroup behavior, and on the social psychology of power.

MICHAEL I. NORTON received his PhD in social psychology from Princeton University in 2002 and is currently assistant professor of marketing at Harvard Business School in Cambridge, MA. His research focuses on the impact of social norms on judgment, decision-making, and behavior, particularly in the interplay between discrimination and political correctness. 